\title{
Playing Ourselves into Feudalism: The Politics and Ethics of Playful Automation
}

\author{
Miguel Sicart \\ IT University of Copenhagen \\ Rued Langgaards Vej 7 \\ 2300 Copenhagen Denmark \\ miguel@itu.dk
}

\author{
Martin Pichlmair \\ IT University of Copenhagen \\ Rued Langgaards Vej 7 \\ 2300 Copenhagen Denmark \\ mpic@itu.dk
}

\section{Introduction}

Automation is everywhere. We fear the robots, but it is in fact a more insidious kind of automation, driven by algorithms and presented in a playful way, that is slowly corroding the social fabric. This "soft automation", the use of algorithms to eliminate semi-skilled white-collar jobs, is transforming services into self-services, and killing the middle class as a result of it.

There is a lot of concern over automation (Vallor, 2014). From the future of work in the face of disappearing jobs (Srnicek and Williams, 2015) to the fear of an Al planet (Bostrom, 2016), we are witnessing a revolution across labor: in the way it is organized, rewarded, and eliminated. We should be afraid of automation. Not only of the robots that will deprive factories from human jobs that require skill and expertise but not an academic education, but also of the quotidian, mundane forms of automation we are silently letting take hold of our daily life.

The explosion of $\mathrm{Al}$ techniques for natural language processing and image recognition, coupled with the ubiquitous presence of powerful smartphones has changed the way we interact with services. Through concepts like Big Data, states and corporations alike are finding solutions to make their services more accessible to users by developing software that can be installed on a smartphone, which is available $24 / 7 / 365$, and that allows users to benefit from engaging with these services when they please. And additionally, they make these engagements pleasurable and fulfilling through playful User Experience designs.

In this paper, we analyze how play has been used as a design framework for the creation of selfservices. Play encourages more appealing and intriguing interfaces and experiences that engage users. However, we will argue that this playful turn is hiding the effective destruction of labor and knowledge that is attached to it. It is doing so by encouraging an aesthetic, pleasurable engagement with the destruction of forms of labor and specialized knowledge. Through playful design, soft automation makes us play and enjoy the success of neoliberal economies of efficiency and accumulation of capital by the few.

This paper presents a critical analysis of soft automation, highlighting how the instrumentalization of play to serve practices of exploitation is abiding and consenting the success of neoliberalism. Building on media theory (Galloway, 2006; Dieter, 2014), aesthetic and critical theory (Baudrillard, 1996) and play theory (Sicart, 2014), we argue that playful soft automation is a corruption of the aesthetic and experiential powers of play as a form of appropriation of the world. At the same time, we will argue that play can be used to subvert soft automation, drawing on the long history of critical play and the arts (Flanagan, 2009; Getsy, 2011).

\section{SOFT AUTOMATION AND PLAYFUL DESIGN}

The use of apps to mediate services marks a transition from services to self-services. This transition involves a displacement of labor from specialized workers with privileged access to the 
inner workings of services, to users being deputized to perform service operations with the aid of software. Professions that used to be the stalwarts of the middle class and that did not require a long, academic education, like bank teller or clerk, are disappearing as we users accept to do that work ourselves, without any intermediaries. The promise of the vanishing intermediaries hides the threat of eliminating those service specialists, like travel agents, who understood how complex systems operated and could navigate them for us. Now we are at the mercy of algorithms such as search engines, which we have to interact with in order to book our next holidays or find that receipt that we need for our taxes (Manovich, 2014, Mittelstadt et al., 2016).

We address the transformation of services into self- services via software applications with the proposal of the concept of "soft automation". Soft both because it is based on software, and because it does not bring forth the fears of the terminator that will kill us, or the car-assembling robot that will steal our jobs. And automation, because these software- based services depend on algorithms to translate the complex systems into an interface that is user- friendly. Soft automation has the effect of displacing labor from specialized workers to users.

Additionally, softly automated services entice their users via playfulness. Research in games as engagement tools has showed that games can be used to increase the satisfaction and engagement and learning in users (Fuchs, Fizek, Ruffino, Schrape, 2014; Walz \& Deterding, 2015). There are successful indications that some forms of gamification and game-based learning actually increase engagement and improve educational results. Play is a powerful instrument to engage users of digital systems, to make them more attached and engaged to their activities, and to translate repetitive, boring, and mildly complex tasks into something more pleasurable. The promise of play is that by making things feel like games, and by structuring the activity using game design techniques, users can play the world, and therefore feel more engaged with the activity at hand (Deterding, 2012).

While controversial (Lieberoth, 2015), this approach has shown to be effective (Márquez Segura et al., 2016). Gamification researchers have argued that redesigns of experiences based on playable interactions have increased user engagement, improved learning, and helped people engage with complicated and complex topics.

This process of playfully contributing to the progress of soft automation manifests in many ways. Facebook researchers recently used 3.5 billion public Instagram photos-carrying 17,000 hashtags appended by users-to train algorithms to categorize images. The gigantic database was built by users engaged in the services offered by Instagram, users that were oblivious about how their digital labor was used. The previous largest effort in training the automation algorithms for image detection was the Google Image Labeler (https://crowdsource.google.com/imagelabeler), a system originally designed by Luis von Ahn, the inventor of ReCAPTCHA, a captcha system that crowdsources the digitalization of books.

In all these developments a general development of soft automation becomes evident. In a first step, specialized labor was transformed into automatable labor that was then outsourced to lesser qualified but paid workers. Amazon's Mechanical Turk is an example of this first stage of soft automation. In a second step, crowdsourcing was employed in order to turn unpaid users into workers. The above examples present this stage of soft automation. We expect the third step to be that even unpaid labor is abolished and machines train each other to learn to perform tasks that used to required human professionals. It is precisely the transition from step two to step three where playfulness is employed in 
order to "pay" users with entertainment instead of wages.

Artists have been aware of this development and offer a critical perspective. Lauren McCarthy's and Kyle McDonald's pplkpr is "an app that tracks, analyzes, and auto-manages" (http://pplkpr.com) its users social relationships. Using a smartwatch and manual input, pplkpr monitors their physical and emotional response to the people around them and promises to "optimize their social life accordingly" (). The app is a critical intervention commenting on the quantified self and on how we outsource our social labor to machines. The Weather Followers by David Colombini (http://www.davidcolombini.com/theweatherfollower s.html) is an example of an art piece that offers expression instead of efficiency and actively engages with the totalitarianism of algorithms. It is the least "smart" weather app in existence. Terra0 (Seidleret al. 2016) is an automated resilience enhancement for ecosystems. This artwork is a forest that uses blockchain-powered algorithms to govern itself. It abolishes human labor as much as possible and uses automated contracts as a way of securing its own interests.

\section{CONCLUSIONS}

Neil Postman famously warned us that we were amusing ourselves to death, consuming media that would distract us from the real dangers and political challenges of our time. In this paper we want to issue a similar warning. Thanks to soft automation, we are slowly playing ourselves into feudalism: we are allowing corporations to automate middle-class jobs, strengthening income inequality and de facto creating a social divide between owners and users. These users don't own anything, they just lease it; and these owners produce the data required to feed the algorithms that deprive them of jobs. And they do so voluntarily, by playing these joyful automated systems.
There is hope, however. The critical work of the artists briefly surveyed in this piece proposes an alternative to the current state of affairs in soft automation and playful design. Critical arts and play allow us to think alternatively about configurations of labor, pleasure, and experience in an increasingly automated society. They also give us instruments for resistance and subversion that allow for the imagination of alternative futures (Frase, 2016; Srnicek \& Williams, 2016). This paper will conclude with a reflection on the artistic methods and practices to mediate soft automation, intended to systematize our understanding of playful artistic practices in the crossroads of labor, automation, and neoliberalism. Digital artists are showing how we can go beyond playing automation and engage in critical experiences that play with automation.

\section{REFERENCES}

Baudrillard, J. (1996) The System of Objects. Verso, London

Bostrom, N. (2016) Superintelligence: Paths, Dangers, Strategies. Oxford University Press, Oxford

Deterding, S. (2012) Gamification: Designing for Motivation, Interactions, 19.4, 14-17

Dieter, M. 2014. 'The Virtues of Critical Technical Practice', Differences, 25.1

Flanagan, M. 2009. Critical Play. Radical Game Design. The MIT Press, Cambridge, Mass.

Frase, P. 2016. Four Futures: Life After Capitalism. Verso, London.

Fuchs, M., Fizek, S., Ruffino, P. Schrape, N. 2014. Rethinking Gamification. Meson Press, Lüneburg

Galloway, A R. 2006. Gaming: Essays on Algorithmic Culture. University of Minnesota Press, Minnesota

Getsy, David J (ed.). 2011. From Diversion to Subversion. Games, Play, and Twentieth- 
Century Art. Penn State University Press,

Pennsylvania

Lieberoth, A. 2015. Shallow Gamification, Games and Culture, 10.3, 229-48

Manovich, L. 2014. Software Is the Message, Journal of Visual Culture, 13.1, 79-81

Mittelstadt, B.D., Allo, P., Taddeo, M., Wachter, S. and Floridi, L. 2016. 'The Ethics of Algorithms: Mapping the Debate', Big Data \& Society, 3.2, $1-21$

Rancière, J. 2013. The Politics of Aesthetics, Bloomsbury, London.

Seidler, P., Kolling, P., and Hampshire, M.. 2016. terra0 - Can an augmented forest own and utilise itself?.

https://terra0.org/assets/pdf/terra0_white_paper 2016.pdf

Sicart, M. 2014. Play Matters. The MIT Press, Cambridge.

Srnicek, N, and A Williams. 2016. Inventing the Future: Postcapitalism and a World Without Work. London: Verso

Vallor, S. 2014. 'Moral Deskilling and Upskilling in a New Machine Age: Reflections on the Ambiguous Future of Character', Philosophy \& Technology, 28.1, 107-24

Walz, S.P and Deterding, S. (eds.), 2015. The Gameful World. The MIT Press, Cambridge 